\title{
Evaluation on Methods in Estimating the Photovoltaic Performances Affected by Module Operation Temperature in Tropical Region
}

\author{
MRR Chand ${ }^{1}$, Firdaus Basrawi ${ }^{1, *}$, Azizuddin Abd Aziz', Zafri Azran ${ }^{2}$, Shaharin Anwar \\ Sulaiman ${ }^{3}$, Afzam Zulkepli ${ }^{1}$, \\ ${ }^{1}$ Energy Sustainability Focus Group, Faculty of Mechanical Engineering, University Malaysia \\ Pahang, 26600, Pekan, Pahang, Malaysia. \\ ${ }^{2}$ Faculty of Health Science, International Islamic University Malaysia, 26000, Kuantan, Pahang, \\ Malaysia \\ ${ }^{3}$ Fundamentals and Applied Sciences Department, University Technology Petronas, Bandar Seri \\ Iskandar, 32610, Perak, Malaysia
}

\begin{abstract}
This research work is intended to evaluate the reliability of commonly utilized empirical correlations of module operation temperature in estimating the photovoltaic performances in tropical region. The Nominal Operation Cell Temperature (NOCT) model, Tropical Field Operation Cell Temperature (tFOCT) model and the experimental back module temperature were selected for evaluation purposes. The models were evaluated by comparing the performance characteristics of a $250 \mathrm{~W}$ monocrystalline photovoltaic module installed at University Malaysia Pahang. The monocrystalline back module temperature and power output as well as the environmental data including both solar irradiation and ambient temperature were monitored to assist the analysis. Based on the 5 consecutive day experimental data, results indicated that the module operation temperature estimated by tFOCT model had the closest value to the experimental back module temperature. Whereas, the temperature estimated by NOCT model showed the highest deviation up to $25.8 \%$ from the experimental back module temperature. However, in terms of estimating the photovoltaic module power output, the NOCT model had the closest value to the experimentally measured power output. The results also indicated that utilizing the back module temperature often mislead the estimation of photovoltaic module power output. In addition, the deviation of estimated power output from NOCT model, tFOCT model and back module operation temperature as compared to the experimental power output were $15.4 \%$, $18.87 \%$ and $21.2 \%$, respectively. Thus, the NOCT model demonstrated better estimation of power output as compared to the experimental result than tFOCT model, and back module temperature. However, better estimation method for tropical regions is still needed because three methods evaluated in this study shows deviation of more than $15.4 \%$ from the measured power output.
\end{abstract}

*Corresponding author: mfirdausb@ump.edu.my 


\section{Introduction}

The growing interest towards the sustainable energy system had boosted the photovoltaic system (PV) for power generation applications. Acquiring the ability of harnessing from $10 \%$ up to $25 \%$ of sun energy, the PV system installation demonstrated $25 \%$ increment in 2015 as compared to previous year ${ }^{1}$. Significant factors such as government incentive, national level policy framework, sophisticated manufacturing technology and reasonable capital cost contributes to the growth of PV technologies. The typical capital cost of $10 \mathrm{~kW}_{\mathrm{p}}$ to $100 \mathrm{~kW}_{\mathrm{p}}$ PV system had reduced from $€ 14,000 / \mathrm{kW}_{\mathrm{p}}$ as reported in 1990 to only $€ 1,270 / \mathrm{kW}_{\mathrm{p}}$ by the end of $2014{ }^{2}$. Additionally, the 27 million tonnes of $\mathrm{CO}_{2}$ reduction achieved by German solely in 2015, manifested the reliability of PV system in reducing the carbon emission ${ }^{2}$. Globally, the cumulative installed capacity of PV system by the end of 2014 is $177 \mathrm{GW}$ where $22 \%$ of the capacity were dominated by Germany and followed by China and Japan with $16 \%$ and $13 \%$, respectively ${ }^{3}$. This progressive move also had assisted upon the evolution of mass PV manufacturing industries especially in China ${ }^{4}$. Dominating $66 \%$ of PV manufacturing industries, China had 9 mega companies in 15 top PV manufacturer list. In addition, several other Asian countries such as Japan, Korea and India also displayed rapid developments in PV markets ${ }^{4}$.

In Malaysia, since the pilot PV system installation in 1998 by the national power company, Tenaga National Berhad (TNB), the PV system had emerged as the one of the options in the Fifth Fuel Diversification Policy introduced in $1999^{5}$. Along with other measures such as feed- in tariff programmes (FiT), income tax reduction and green technology financing scheme, the PV technology displayed positive pronounced breakthrough in power generations industry in Malaysia. The total cumulative installed PV capacity reported in Malaysia by the end of 2014 was $168 \mathrm{MW}$ in which $88.5 \mathrm{MW}$ were installed solely in that year ${ }^{6}$. Almost $98 \%$ of the installation work performed were grid connected, highlighting the effectiveness of the implemented FiT programme. Assisted with programmes such as, net metering and tax allowance, the PV markets were targeted to expand up to $22.4 \mathrm{GW}$ in commercial and industry sectors as well as $8.45 \mathrm{GW}$ in residential sectors by the end of $2035^{6}$.

The projection on the growth of PV markets in Malaysia, encourage further improvements in system designing and sizing procedures. The necessity of accurate energy yield forecasting were observed to be crucial in attracting investors while assisting the system designers in outlining economical system with optimum performances. Adapting the performances at Standard Testing Condition (STC) to estimate the PV power output, often mislead the energy yield forecasting. Generally, the rated performance at STC are correspond to solar irradiance of $1 \mathrm{~kW} / \mathrm{m}^{2}, 25^{\circ} \mathrm{C}$ ambient temperature and air mass at 1.5 . In reality, the real operation condition of PV varies much from the STC which influence the power output and efficiency of PV modules as reported in many literatures especially in tropical climate applications ${ }^{7-10}$ . Amin, Lung and Sopian ${ }^{11}$ had demonstrated that efficiency and power output of crystalline module decreases in tropical climate applications where the recorded averaged performance ratio was not exceeding 95\%. In addition, Jia-Ying Ye, Ding, Reindl and Aberle ${ }^{12}$ also had study on the effect of fluctuating irradiance in tropical region where the result indicates that the efficiency of crystalline module decreases due to the fluctuations. Furthermore, installation factors such as orientations, mounting, tilt angle and intensity of sunlight exposures also affects the performances of PV modules. However, these factors are avoidable with proper designing and installations ${ }^{13}$. Unfortunately, the degradation of rated performances due to the PV module operation temperature is unavoidable as it is a function of ambient temperature and solar irradiation ${ }^{14}$.This affect is further prominent in tropical climate areas such as Malaysia where the increase in ambient temperature degrades the power output of the solar panel. The voltage reduction caused by higher operation temperature, lead 
to huge challenges toward PV system designers on estimation the actual power output of PV modules. One of the well-established method on forecasting the power output as function of ambient temperature and cell temperature is the nominal operation cell temperature (NOCT). The NOCT is the standard initiated by IEC on characterising the operation temperature where it is defined at $800 \mathrm{~W} / \mathrm{m}^{2}$ solar irradiance, $20^{\circ} \mathrm{C}$ ambient temperature and wind speed of about $1 \mathrm{~ms}^{-1}$ with the module orientated at $45^{\circ}$ south exposed to outdoor environment ${ }^{15}$. Most PV manufacturer's technical sheets ranged the NOCT from $40^{\circ} \mathrm{C}$ to $50^{\circ} \mathrm{C}$, in which higher NOCT denoting lower performances at higher ambient temperature ${ }^{16}$. There were also other empirical models developed in order to estimate the module operation temperature and subsequently the power output of PV modules. However up to date, there is no studies are made on evaluating the conciseness of the respective models towards the power output estimation of standalone photovoltaic system in tropical region.

Hence, this research is intended to evaluate several commonly utilize models on estimating the module operation temperature and subsequently the power output of PV modules in standalone system that is exposed to topical climate conditions. The Nominal Operation Cell Temperature (NOCT) model, Tropical Field Operation Cell Temperature (tFOCT) model and experimental back module temperature were selected for evaluation on estimating PV power output. The models were evaluated through comparing the performance characteristic of $250 \mathrm{~W}$ monocrystalline module installed at University Malaysia Pahang. The respective module power output, and back module temperature as well as the solar irradiation and ambient temperature data were collected to assist the analysis.

\section{Materials and Methods}

\subsection{The Experimental Procedures}

In order to evaluate the reliability of power output estimation through NOCT, tFOCT and back module temperature methods, an experiment setup was developed at University Malaysia Pahang facility located at $2^{\circ} 47^{\prime} 41.9^{\prime \prime} \mathrm{N} 104^{\circ} 12^{\prime} 11.5^{\prime \prime}$ E in Pekan, Pahang, Malaysia. A standalone PV system compromised of a $250 \mathrm{~W}$ mono-crystalline (c-Si) module integrated to a lead-acid storage battery, charge controllers and DC load as illustrated in Fig 1 was installed.

Table 1 summarize the technical parameters of the installed component available in the PV system. The c-Si was employed in the experimental setup because of its high utilization factor in Malaysia. It also acquired higher efficiency as compared to other crystalline and thin film module available in Malaysia in which the reported efficiency is $15.39 \%$ at STC. The c-Si module was installed at $10^{\circ}$ tilt angle with an open rack mounting system to avoid heat accumulation which may mislead the temperature measurement. Formulated based on IEC 61215 standard, the module NOCT reported by the manufacturer is $46^{\circ} \mathrm{C}$ with $\pm 2{ }^{\circ} \mathrm{C}$ tolerance. In addition, to reduce the cable and wire size, the c-Si was connected to a 75Ah lead acid battery bank with $24 \mathrm{~V}$ system voltage configuration. In between, a PWM charge controller with maximum amperage rating of $20 \mathrm{~A}$ was employed. The charge controller is responsible on controlling the charging as well as the discharging process of the respective standalone PV system.

The system also includes a dump DC load of a $24 \mathrm{~V}$ xenon headlight with rated power consumption of $100 \mathrm{~W}$ for two purposes. Foremost, the load is essential in dumping the excessive energy generated by the c-Si module. Secondly, the dump load is also utilized to avoid the charge controller to initiate the PWM charging process. The charge controller were programmed to perform PWM charging once the SOC of the battery reached up to $80 \%$ of the rated capacity. Upon entering the PWM charging phase or Boost Charge phase, the 
charging current is reduced to avoid battery overheating and gassing while ensuring longer battery life. However, it is not desirable in the experimental procedure as it alters the characteristic of c-Si module where lower power output will be recorded.

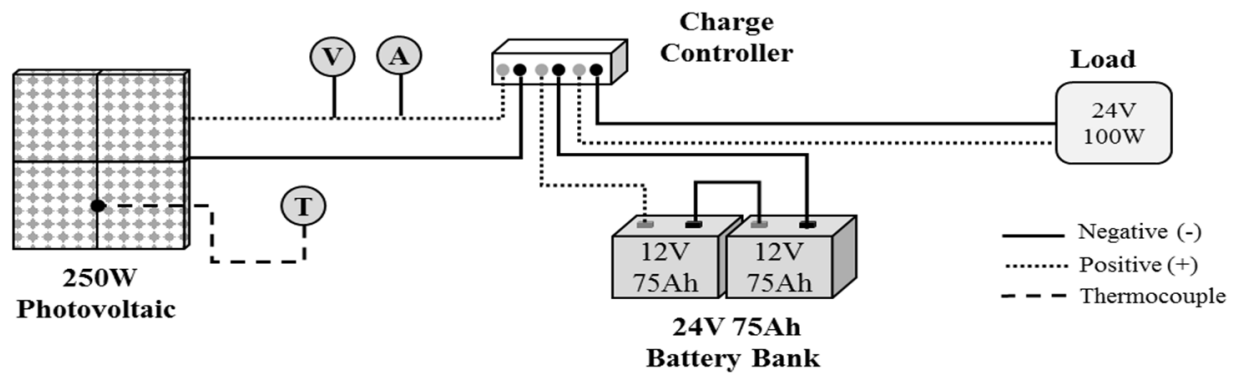

Fig. 1. The schematic of standalone photovoltaic system installed in University Malaysia Pahang Facility.

Table 1. The technical parameters of installed PV system.

\begin{tabular}{|c|c|}
\hline \multicolumn{2}{|c|}{ Mono-Crystalline Module } \\
\hline Rated Power, $\mathrm{P}_{\mathrm{Max}}[\mathrm{W}]$ & 250 \\
\hline Voltage at Maximum Power, $\mathrm{V}_{\mathrm{mpp}}[\mathrm{V}]$ & 31.26 \\
\hline Current at Maximum Power, $\mathrm{I}_{\mathrm{mpp}}[\mathrm{A}]$ & 8.00 \\
\hline Open Circuit Voltage, $\mathrm{V}_{\mathrm{oc}}[\mathrm{V}]$ & 36.96 \\
\hline Short Circuit Current, $\mathrm{I}_{\mathrm{sc}}[\mathrm{A}]$ & 8.8 \\
\hline Effective Area, $A_{\text {eff }}\left[\mathrm{m}^{2}\right]$ & 1.46 \\
\hline Efficiency, $\eta[\%]$ & 15.39 \\
\hline NOCT $\left[{ }^{\circ} \mathrm{C}\right]$ & $46 \pm 2$ \\
\hline Temperature Coefficient, k [\%/K] & -0.45 \\
\hline \multicolumn{2}{|c|}{ Sealed Lead Acid Battery } \\
\hline Rated Voltage, $V_{\text {Batt }}[\mathrm{V}]$ & 12 \\
\hline Capacity, C [Ah] & 75 \\
\hline Number of battery, $n$ & 2 \\
\hline Connection & Series \\
\hline Battery Bank Voltage [V] & 24 \\
\hline Total Daily Useable Energy Capacity [kWh] & 1260 \\
\hline \multicolumn{2}{|c|}{ Charge Controller } \\
\hline Nominal System Voltage [V] & 24 \\
\hline Maximum PV Input Voltage [V] & 50 \\
\hline Nominal Charge/Discharge Current [A] & 20 \\
\hline \multicolumn{2}{|c|}{ Load - Xenon Headlight } \\
\hline Operation DC Voltage [V] & 24 \\
\hline Power Consumption [W] & 100 \\
\hline Operation Hours [h] & 8 \\
\hline Daily Energy Consumption [kWh] & 800 \\
\hline
\end{tabular}

Hence, the dump load is essential in maintain the SOC of the battery in the range of $30 \%$ to $80 \%$ or in the Bulk charging phase where $100 \%$ of the available c-Si module power output is consumed into the battery or supplied directly to the load. The load was switched on for 8 hours daily from 11p.m to 8p.m during the experimental work. 
The voltage of the c-Si module was acquired through voltage divider circuity with maximum reading capability of 50V. On the other hand, the ACS712 current sensor was used to obtain the current generated by the c-Si module. Both voltage and current sensor were calibrated prior to experimental operation with sensitivity at $100 \mathrm{mV} / \mathrm{V}$ and $100 \mathrm{mV} / \mathrm{A}$, respectively. Those sensor were installed in between the c-Si module and the charge controller wiring as shown in Fig 1, where voltage and current sensor were denoted with V and A symbol, respectively. In addition, the data on module back temperature is also essential in analysing the power output derating. Hence, a K-type thermocouple was laminated on the back surface of the c-Si module with conductive sealant and tape to insure good thermal contact.

Furthermore, the site meteorological characteristic acknowledged during the experimental process were the solar irradiance and ambient temperature .The instrument utilized for monitoring the global solar irradiance was a pyranometer with sensitivity ranging from $5 \mu \mathrm{V} / \mathrm{Wm}^{-2}$ to $20 \mu \mathrm{V} / \mathrm{Wm}^{-2}$. The pyranometer was installed parallel accordingly to the inclined plane of the c-Si module to obtain the actual solar irradiance acting of the module surface. The LM-35 sensor with accuracy of $\pm 0.5^{\circ} \mathrm{C}$ was utilised for measuring the ambient temperature.

All the respective data were logged at 5s interval for 10 hours daily from 9.00 a.m to 6 p.m. The experiment was conducted for 5 consecutive days from $11^{\text {th }}$ June 2016 to $15^{\text {th }}$ June 2016. The gathered experimental power output of the c-Si module was then compared to simulated power output which is a function of solar irradiation and ambient temperature as formulated is Equ. $1^{17}$.

$$
P=P_{\max } K_{G} K_{T}
$$

The $K_{G}$ and $K_{T}$ is the coefficient of solar irradiation and operation temperature, receptively. The $K_{G}$ is ratio of measured global solar irradiance, $G_{T}$ to the solar irradiance at STC, $G_{S T C}$ which is $1000 \mathrm{~W} / \mathrm{m}^{2}$ as formulated in Equ. 2

$$
\begin{aligned}
& k_{G}(t)=\frac{G(t)}{G_{S T C}} \\
& k_{T}(t)=\left[1+\left(\frac{\beta}{100}\right) \times\left(T_{C}(t)-T_{S T C}\right)\right]
\end{aligned}
$$

On the other hand, the $K_{T}$ was calculated based on Equ. 3 formulation, where $\beta$ is the temperature coefficient of the c-Si module provided by the manufacturer, $T_{C}$ is operation cell temperature and $T_{S T C}$ is the ambient temperature at STC.

\subsection{Power Output Estimation Method}

There were 3 method utilized to calculate the $T_{C}$ in order to identity the appropriate model suitable for PV module power output estimation in tropical region. All the calculated $T_{C}$ were then substituted into Equ.3 and subsequently into Equ.1 to estimate the power output. The method are listed as follows;

\subsubsection{Nominal Operation Cell Temperature, NOCT}

This is the most common method utilized on estimating the cell temperature of both crystalline and thin film module. The NOCT value provided by the manufacturers was substituted into Equ.4 to estimate the operation cell temperature, $T_{C}$. In this case, the NOCT 
value of the c-Si module listed in Table 1 was used to calculate the cell temperature, $T_{C}$ of the module.

$$
T_{c, N O C T}(t)=\frac{N O C T-20}{800} \times G_{T}(t)+T_{a m b}(t)
$$

\subsubsection{Tropical Field Operation Cell Temperature, tFOCT}

Ya'acob, Hizam, Khatib, Radzi, Gomes, Marhaban and Elmenreich ${ }^{18}$ had introduced a novel method on estimating the operation cell temperature of c-Si module which was formulated for tropical climate application only. The author had provided a concise arguments on revising the Equ.4 for topical field only where modification on the standard climatic parameters were performed while replacing NOCT into tFOCT as formulated in Equ.5. The value for $\mathrm{tFOCT}$ suggested by the respective author was $52.5^{\circ} \mathrm{C}$ for $\mathrm{c}-\mathrm{Si}$ module.

$$
T_{c, t F O C T}(t)=\frac{t F O C T-34}{886} \times G_{T}(t)+T_{a m b}(t)
$$

\subsubsection{Back Module Temperature}

The back module temperature, $T_{b m}$ that was collected by laminating a thermocouple at the back surface of the module. Thus the cell temperature was assumed to be identical with the measured temperature as shown below.

$$
T_{C}=T_{b m}
$$

\section{Results and Discussion}

\subsection{The Experimental Output}

Fig. 2 illustrates the 15 minute interval average data of solar irradiance and c-Si module power output from 9.00 a.m to 6.00 p.m for the respective 5 consecutive days. The maximum solar irradiance recorded during the experimental period was $1,197 \mathrm{~W} / \mathrm{m}^{2}$ where daily, the site received an average of $4.9 \mathrm{kWh} / \mathrm{m}^{2}$ of solar insolation. The peak average solar irradiance was $858 \mathrm{~W} / \mathrm{m}^{2}$ recorded at 1.30 p.m as shown in Fig. 2 in which the c-Si module also displayed the peak output of $175 \mathrm{~W}$. In average, the c-Si module successfully generated $1.1 \mathrm{kWh}$ of electrical power daily which were $15.37 \%$ of the available average solar energy. At $1000 \mathrm{~W} / \mathrm{m}^{2}$, the $250 \mathrm{~W} \mathrm{c-Si}$ module only able to generate $205 \mathrm{~W}$ of electrical power where it was $18 \%$ lower than rated power output at STC. As the pyranometer was placed nearby to the c-Si module, avoiding loses due to orientation and with regular cleaning preventing dust accumulation, the operation module temperature was observed to be primary factor contributing to the power output derating.

The latter phenomenon is best described through comparing the ambient temperature and the efficiency of the c-Si panel as shown in Fig. 3. As illustrated, the efficiency of the c-Si module decreased at higher ambient temperature because of heat accumulation on the module surfaces which increased the operation temperature. As a result, lower power output was recorded as compared to the rated specification that were measured at STC conditions. Theoretically, this is due to the metallurgical characteristic of the crystalline structure of the c-Si module where higher temperature alters the band gap energy of the c-Si cell. The 
alteration resulted in the reduction of the module voltage which is best observed through monitoring the open circuit voltage.

Fig.4 illustrate the relation between average increased of back module temperature, $T_{b m}$ compared the ambient temperature, $T_{a m b}\left(T_{b m^{-}} T_{a m b}\right)$ against the solar irradiance. It is obvious that the back module temperature increased relatively to the solar irradiance level. At the range of $200 \mathrm{~W} / \mathrm{m}^{2}$ to $1,000 \mathrm{~W} / \mathrm{m}^{2}$, the back module temperature increased up to $2^{\circ} \mathrm{C}$ to $14^{\circ} \mathrm{C}$ over the ambient temperature. The maximum recorded back module temperature was $58.3^{\circ} \mathrm{C}$ with maximum difference over the ambient temperature of $14.4^{\circ} \mathrm{C}$. It should be noted that the highest value of the back module temperature is not appeared at higher solar irradiation, but it shows at lower solar irradiation ranging from $700 \mathrm{~W} / \mathrm{m}^{2}$ to $900 \mathrm{~W} / \mathrm{m}^{2}$. This is because the increase in module temperature is the product of cumulative heat transfer process. In other word, higher module temperature was recorded prior to 11.30 p.m. up to 3.00 p.m. which resulted due to higher heat transfer rate at previous hour.

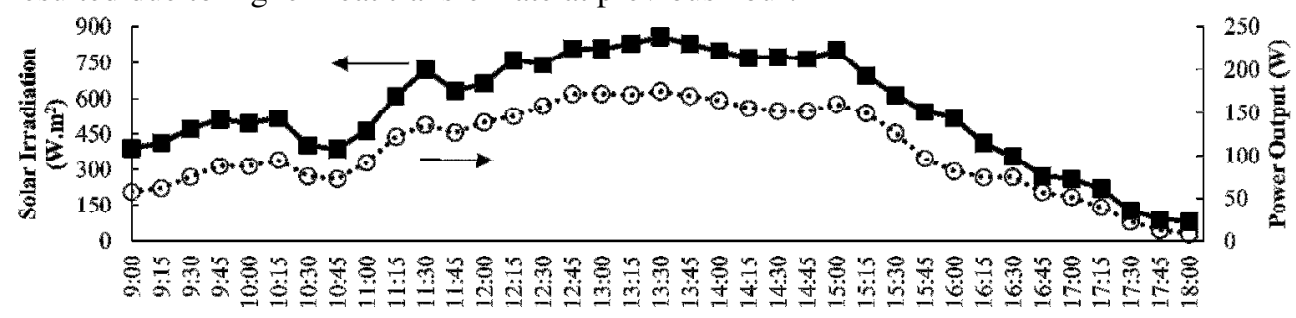

Fig. 2. The Mean solar Irradiation data and power output of PV panel.

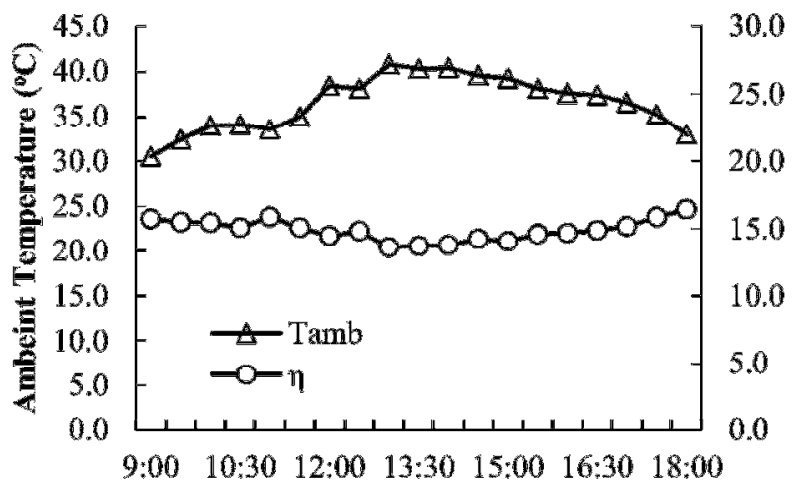

Fig. 3. The module efficiency and ambient temperature on 11th May 2016.

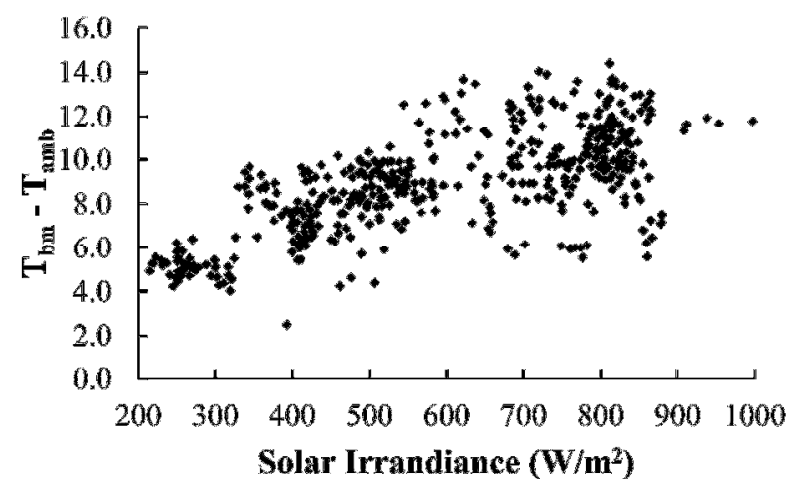

Fig. 4. The temperature difference of Tbm and Tamb against solar irradiation. 
In summary, the experimental results demonstrated that the module operation temperature has significant effect on the power output in tropical climate application. Based on the monitored data, the average performance ratio of the c-Si module which is ratio of generated power output to the power output at STC is only 0.8 . In other word, the c-Si module suffer almost of $20 \%$ of power output derating at tropical climate. Hence, in order to estimate the losses incurred by the c-Si module, a reliable estimation method is required.

\subsection{The Module Operation Temperature Estimation}

The averaged module operation temperature by different methods at 30 minutes interval are shown in Fig.5.

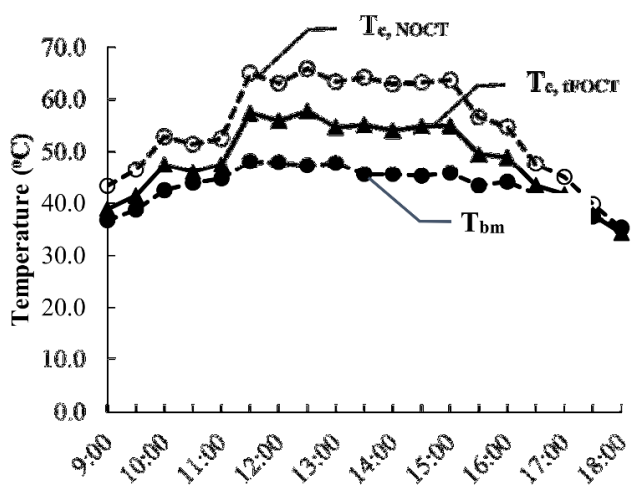

Fig. 5. The gathered module operation temperature.

As shown in Fig. 5, the estimation of module operation temperature shows that the HFOCT model, $T_{c, t F O C T}$ provides the closest value to the back module temperature, $T_{b m}$ that were obtained through experiment. On the other hand, the estimated $T_{c \text {, NOCT }}$ displayed higher module operation temperature in comparison to both $T_{c, \text { NOCT }}$ and $T_{b m}$. Deviation with the back module temperature as the reference was calculated, and the average deviation of $10.7 \%$ and $25.8 \%$ were observed for $T_{c, t F O C T}$ and $T_{c, \text { NOCT }}$, respectively. Furthermore, the deviation was more severe at higher ambient temperature and solar irradiation which from 11.30 a.m to 3.00 p.m as illustrated in Fig.5. The maximum temperature difference between the $T_{c \text {, NOCT }}$ and the $T_{b m}$ was $26.5^{\circ} \mathrm{C}$, whereas only $16.3^{\circ} \mathrm{C}$ was recorded between $T_{c, t F O C T}$ and $T_{b m}$. The average temperature difference for $T_{c, t F O C T}$ and $T_{c, N O C T}$ as compared to the $\mathrm{T}_{\mathrm{bm}}$ were $5.6^{\circ} \mathrm{C}$ and $11.6^{\circ} \mathrm{C}$, respectively.

Furthermore, no significant temperature difference for $T_{c, t F O C T,} T_{c, N O C T}$ and $T_{b m}$ in the morning period from 9.00 a.m to 11.00 a.m and almost identical result approaching the evening were observed as illustrated in Fig.5. Lower ambient temperature and solar irradiation during those periods allows dissipation of the accumulated heat in the c-Si module to the surroundings while achieving equilibrium towards the ambient temperature. Hence, the $T_{c, t F O C T}, T_{c, t F O C T}$ and $T_{b m}$ demonstrated closer value of operation module temperature towards the ambient temperature.

\subsection{The Power Output Estimation}

In order to evaluate both experimental and estimated module operation temperature, the power output of the c-Si module were estimated based on the obtained result. The power output of the c-Si was estimated through substituting the obtained result into Equ.3 to calculate the derating coefficient caused by module operation temperature, $K_{T}$. Along with the solar irradiation data which subsequently substituted into Equ.2 to acquire the $K_{G}$, the power output of the c-Si module was calculated by means of Equ. 1 where $P_{\max }$ is $250 \mathrm{~W}$. The 
calculation were performed for all the 5 respective consecutive days and the data were averaged into 15 minute interval as shown in Fig.6. As shown in Fig.6, 4 different power output were compiled including the experimental power output, $P_{e x}$, the power output based on experimental back module temperature, $P_{b m}$, the power output based on NOCT model, $P_{N O C T}$ and the power output based on tFOCT model, $P_{t F O C T}$.

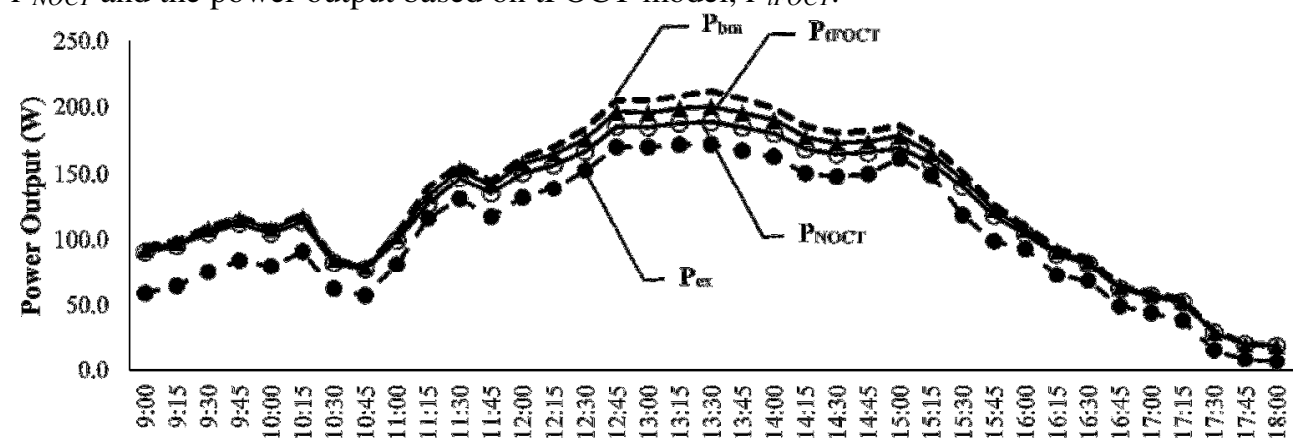

Fig. 6. The experimental and the calculated average power output of c-Si module.

It was found that $P_{N O C T}$ shows the closest value to the experimental power output, $P_{e x}$ than both $P_{b m}$ and $P_{t F O C T}$. Despite the large deviation demonstrated by the NOCT model in estimating the module operation temperature as shown in Fig.5, the NOCT model had smallest difference as compared to the experimental result in power output estimation. Deviation was calculated with $P_{e x}$ as the reference, and the average deviation of $P_{N O C T}$ was $15.4 \%$. On the other hand, Fig. 6 also demonstrated that estimating the power output of PV modules by accounting the back module temperature often lead to inaccuracy as reported in ${ }^{19}$. Both $P_{b m}$ and $P_{t F O C T}$ displayed high deviation with an average error of $21.2 \%$ and $18.7 \%$ respectively. It should be noted that even though the tFOCT model estimate the closest value of module operation temperature to the back module temperature, the estimated $P_{t F O C T}$ is not accurate as compared to the $P_{\text {NOCT }}$. Although, the tFOCT were determined at topical region condition, the tFOCT model still requires further consideration in estimating the experimental power output. The deviation is suspected to be occurred because of the method implemented on obtaining the temperature profile from the c-Si module. However, the estimation of power output through tFOCT model is still acceptable in which it only has the difference of $3.3 \%$ from NOCT-model in term of deviation.

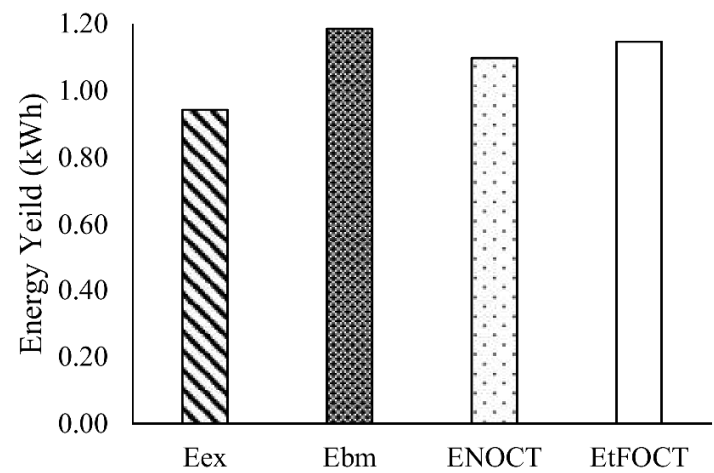

Fig. 7. The average energy yield from experimental and calculated data.

The bar graph shown in Fig.7 illustrates the average energy yield of 5 consecutive days obtained based on the experimental and estimation methods. The difference of energy yield based on NOCT model, tFOCT model and back module temperature from the experimental result were $14.5 \%, 18.3 \%$ and $20.3 \%$, respectively. Such variation may result in higher energy estimation during designing process as well as lower PV capacity estimation in the 
sizing process which in turn affects the economic performances. Hence, more extensive improvement on the power output estimation method is also required for tropical climate condition.

In summary, estimating the power output through back module temperature profile is not recommended because it does not represent the actual cell temperature NOCT model is still the most suitable method for estimating the power output of c-Si module in tropical climate region. However, several modification perhaps on the NOCT value provide by the manufacturer should be performed to obtain better result.

\section{Conclusion}

An experiment set up were developed in order to evaluate two models in estimating the module operation temperature and the power output of a c-Si module, NOCT and HFOCT. The experimental result shows that the tFOCT model provide better estimation if back model temperature is used as reference temperature. The average deviation of $10.7 \%$ and $25.8 \%$ were observed for tFOCT and NOCT, respectively. It was also found that NOCT model provides much better estimation of power output than tFOCT model in comparison to the experimental power output. The average deviation for power output as compared to experimental result was $15.4 \%$ and $18.7 \%$ for NOCT and tFOCT, respectively. Furthermore, the results also indicated that the power output estimation through back module temperature has the highest deviation, and therefore it is not appropriate method. This is because of the back module temperature failed to represent the actual module operation temperature where higher reading should be obtained. Internal heat accumulation due to electron movement as well as surface convection subjected by the back surface were several factors resulting to the error. Thus, both NOCT model and tFOCT model were observed to be suitable for c-Si module power output estimation. But, the NOCT model demonstrated better estimation of power output than tFOCT model. However, better estimation method for tropical regions is still needed because three methods evaluated in this study shows deviation of more than $15.4 \%$ from the measured power output.

The author would like to acknowledge the authority of Malaysia Ministry of Education and University Malaysia Pahang upon the funding provided for the research under grant RDU140119 or FGRS/1/2014/TK06/UMP/01/1

\section{Nomenclature}

\begin{tabular}{lll}
\multicolumn{3}{l}{ Abbreviation } \\
PV & $:$ & Photovoltaic \\
c-Si & $:$ & Monocrystalline \\
STC & $:$ & Standard Testing Condition \\
FiT & $:$ & Feed In Tariff
\end{tabular}

$\begin{array}{lll}\text { Symbols } & & \\ \text { NOCT } & : & \text { Nominal Operation Cell Temperature }\left[{ }^{\circ} \mathrm{C}\right] \\ t F O C T & : & \text { Tropical Field Operation Cell Temperature } \\ P & & \text { Power Output }[\mathrm{W}] \\ k & : & \text { Derating Coefficient } \\ T & : & \text { Temperature }\left[{ }^{\circ} \mathrm{C}\right] \\ \beta & & \text { Temperature Coefficient }[\% / \mathrm{K}] \\ G & : & \text { Global Solar Irradiation }\left[\mathrm{W} / \mathrm{m}^{2}\right]\end{array}$




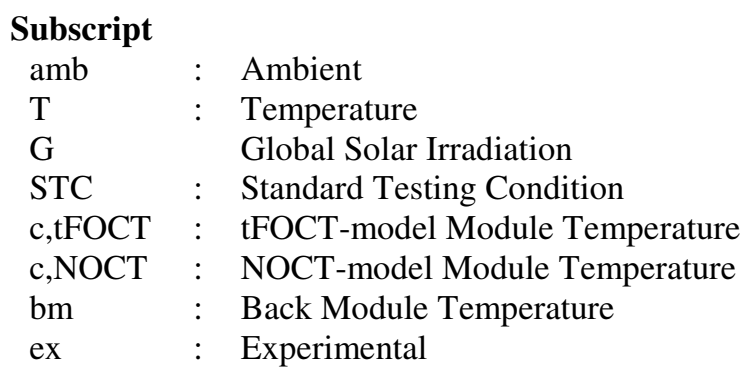

\section{References}

1. IEA, Snapshots of Global Photovoltaic Market (2016).

2. Fraunhofer ISE :Photovoltaic Report June (2016).

3. IEA, Trends 2015 in Photovoltaic Applications (2015).

4. Sahu, B.K., Renew. Sust. Energ. Rev., 43, 621 (2015).

5. Mekhilef, S., et al., Renew. Sust. Energ. Rev., 16, 386 (2012).

6. Ong, H.C., T.M.I. Mahlia, and H.H. Masjuki, Renew. Sust. Energ. Rev., 15, 639 (2011).

7. (SEDA), S.E.D.A.M., National Survey Report of PV Power Aplications in Malaysia 2014. (2014).

8. Basrawi, F., T. Yamada, and S.y. Obara, Appl. Energ., 121, 174 (2014).

9. Sharma, R. and G. Tiwari, Appl. Energ.,. 92, 644 (2012).

10. Saber, E.M., et al., Energy, 71, 588 (2014).

11. Pillai, R., et al., Renew. Energ., 72, 140 (2014).

12. Amin, N., C.W. Lung, and K. Sopian, Renew. Energ., 34, 1939 (2009).

13. Ye, J.-Y., et al., Enrgy. Proced. 33, 238 (2013).

14. Ye, Z., et al., Sol. Energy, 88, 80 (2013).

15. Bayrakci, M., Y. Choi, and J.R. Brownson, Enrgy. Proced., 57, 745 (2014).

16. Muller, M. Measuring and Modeling Nominal Operation Cell Temperature (NOCT). in PV Performance Modeling Workshop. (2010).

17. García, M.A. and J. Balenzategui, Renew. Energ., 29, 1997 (2004).

18. Skoplaki, E. and J. Palyvos, Sol. Energy, 83, 614 (2009).

19. Ya'acob, M.E., et al., J. Renew. Sustain. Ener., 6, 033134 (2014).

20. Alonso García, M.C. and J.L. Balenzategui, Renew. Energ., 29, 1997 (2004). 